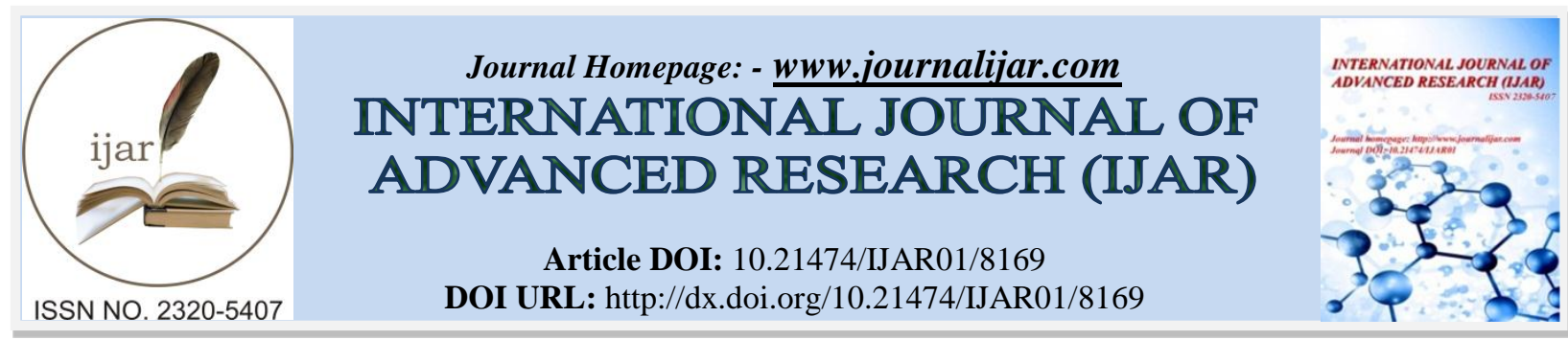

RESEARCH ARTICLE

\title{
"COMPLICATIONS OF PREGNANCY IN ADOLESCENT WOMEN WHO COME TO CONSULT THE RURAL MEDICAL UNIT ICH-EK.
}

\section{Betty Sarabia Alcocer ${ }^{1}$, Luis Alberto Núñez Oreza $^{2}$, Betty Mónica Velázquez Sarabia ${ }^{3}$, Priscilla Karmina} Velázquez Sarabia ${ }^{4}$, Julio Antonio Gutiérrez González ${ }^{5}$, Lidia María Maas Ortegón ${ }^{6}$, Paulino Tamay Segovia $^{2}$, Selene Blum Domínguez ${ }^{2}$, Patricia Margarita Garma Quen ${ }^{7}$, Rafael Manuel de Jesús Mex Álvarez ${ }^{7}$ and Ángel Arturo Ake Ordoñez

1. Professor and researcher at the Faculty of Medicine of the Autonomous University of Campeche.

2. Center for Biomedical Research. Autonomous University of Campeche.

3. Doctor Surgeon graduated from the Faculty of Medicine of the U.A.C.

4. Law graduate and researcher.

5. Professor and researcher of the engineering Faculty of the Autonomous University of Campeche.

6. Professor and researcher of the Faculty of Law of the Autonomous University of Campeche.

7. Professor and researcher at the Faculty of Biochemistry of the U.A.C.

8. Student of the Licentiate Medical Surgeon.

\section{Manuscript Info}

..........................

Manuscript History

Received: 08 October 2018

Final Accepted: 10 November 2018
Published: December 2018

\section{Abstract}

Objective: To identify the most common complications of adolescent pregnancy that come to consult the ICH-EK Clinic.

Material and methods: A descriptive, cross-sectional and retrospective study was conducted, reviewing a total of 32 patients with a diagnosis of adolescent pregnancy; looking for the presence of urinary tract infection, vaginitis, anemia and premature birth The use of postpartum contraception methods associated with this pathology. Results: Vaginitis was present in 8 patients $(25 \%)$, urinary tract infection in 7 patients $(21 \%)$, anemia 3 patients $(9 \%)$ and premature delivery 1 patient (4\%); The most used contraceptive method was the IUD $11(34 \%)$. The vaginal delivery was the most frequent 28 patients (87\%), cesarean section 3 patients $(9 \%$.)

Conclusions: In adolescent pregnancy the main complication is vaginitis.

Copy Right, IJAR, 2018,. All rights reserved.

\section{Introduction:-}

Pregnancy in adolescents is what occurs during the adolescence of the mother, defined by the WHO World Health Organization as the lapse of life between 10 and 19 years of age. It is also usually designated as early pregnancy, because it occurs before the mother has reached enough emotional maturity to take on the complex task of motherhood. ${ }^{1}$

Although in many cultures the idea persists that women should start their reproductive life early, there are several arguments that contradict it.

Corresponding Author:-Betty Sarabia Alcocer.

Address:-Professor and researcher at the Faculty of Medicine of the Autonomous University of Campeche. 
The WHO considers as a risk pregnancy the one that occurs in women under 20 years of age, since it is the main cause of mortality of young women between 15 and 19 years of age due to complications related to childbirth, and abortions performed in risk conditions. ${ }^{1}$

\section{Some indicators that describe the problem:}

Worldwide, one out of every ten births corresponds to a teenage mother and fertility rates range between 05 and 200 live births per 1,000 adolescents, the highest being in Africa and Latin America. ${ }^{2}$

In developing countries, according to the 2006 World Youth Report One out of every six births corresponds to young people aged 15 to 19 One in three women give birth before the age of 20 . The births of women under 20 years of age represent $17 \%$ (14 million births a year worldwide). ${ }^{3}$

Each year, more than 4.4 million adolescents undergo an abortion; of those abortions, $40 \%$ are performed in poor conditions.

The dimension of the problem is greater than that reflected in the previous figures, given that these do not take into account births in children under 15 years, which represent a figure to consider. The Latin American Demographic Center (CELAM) estimates that the percentage of births of teenage mothers is rather close to 20 percent, while other agencies, such as UNICEF and UNIFEM, establish it between 15 and 26 percent. In the indigenous population of Venezuela, early motherhood is a feature of the pattern of reproductive behavior that appears even more accentuated. The frequency of births in adolescents is higher among indigenous youth, whose rate rises to 151 births per thousand women aged 15 to 19 years, compared to 89 estimated at the national level. ${ }^{4}$

However, it is worth noting that the estimates available for the last few years reveal a certain decrease in the adolescent fertility rate in the indigenous population, which has fallen from 200 to 151 per thousand between 2006 and 2007. ${ }^{5}$

There are several variables that influence the appearance of motherhood and fatherhood in adolescence, making it difficult to separate one from the other. However, they can be grouped into three categories: internal or proper factors of the adolescent and external factors or the context in which it operates. ${ }^{6}$

Adolescence can be divided into three stages with different characteristics and in turn with different ways of facing a pregnancy:

Early adolescence (13 to 14 years old):

Linked to her mother, denial of pregnancy, motherhood causes depression and isolation, there is no place for the father. The man is absent in his plans.

\section{Average adolescence (14 to 16 years old):}

Dramatization of the body and emotional experience, feels possessive in relation to the fetus, which in turn is experienced as an instrument of the affirmation of independence of the parents. His attitude is ambivalent: of guilt and pride. The father has a place: The man is considered important as a hope in the future.

\section{Late adolescence (17 to 19 years old):}

Adaptation to the impact of reality, maternal feelings. Search for affection and commitment on the part of the male and establishment as a future companion.

That is why a teenager who becomes pregnant will behave as befits the time of life in which she is traveling, without maturing to later stages by the simple fact of being pregnant; they are pregnant teenagers and not pregnant very young. ${ }^{3}$

\section{Among the internal factors include:}

Start of sexual activity without having information and preventive resources at your fingertips; resistance to the use of contraceptive methods; feeling of omnipotence characteristic of adolescence: "what happened to my friend does not happen to me"; lack of interest in school, family or community activities; escape from dysfunctional family groups (with problems); influence of alcohol and other drugs, which limit the control of impulses; inexistence of a life project; perception of few or no opportunities for success and lack of expectations other than motherhood; fulfillment of gender assignments constructed in their context, "such as the need to have children to prove femininity 
or to prove virility through sexual initiation and procreation"; living in communities (such as rural areas) or schools where early pregnancies are common and considered to be natural; grow in impoverished conditions; being the daughter of a teenage mother ${ }^{7}$

External factors: Scarce or inadequate sex education programs; insufficient guidance services and adolescent health care; myths and stigmas about the use of contraceptives; little or no offer of contraceptive methods; gender assignments based on a female role of dependence and service to men (even in the sexual sphere) and focused on reproduction and domestic functions; stimulation of the context to have sexual relations, especially by the media (television, movies, music, videos, magazines ...), peers or partners and predominant cultural models; pressures, sexual harassment or threats of abandonment by man; sexual violation. ${ }^{8}$

The population aged 16 years or younger who becomes pregnant has a higher risk for her and her child compared to older adolescents.

Adolescents who become pregnant with a time interval of less than 5 years between menarche and delivery are considered a risk factor for unfavorable perinatal results. Between 10 and 14 years old there are higher percentages of low birth weight, depression at birth, pregnancy-induced hypertension, high maternal perinatal mortality and morbidity and a higher percentage of cesarean sections. ${ }^{9}$

When there is little development of the gonadal hypothalamus axis during this period (before 5 years after the menarche), it is necessary that the birth is artificially triggered, if spontaneously this has not occurred. ${ }^{10}$

The morbidity and mortality of pregnant adolescents in Latin America can be similar to that of the group of adult women if they are given adequate prenatal and delivery care.

The adolescent father is absent in decision making within the reproductive event, lack of commitment and even rejection of the respective family. $10 \mathrm{He}$ usually abandons his studies. He has jobs and income of lower level than his peers, there is a higher divorce rate, increased stress and more frequent emotional disturbances due to a negative reaction of the environment that surrounds him. ${ }^{11}$

\section{Material And Methods:-}

The present study is descriptive, cross-sectional, and retrospective carried out in the ICH-EK clinic. The sample consisted of a total of pregnant adolescent women over 13 years of age and under 19 years of age belonging to the following localities: San Francisco Suc-Tuc, Crucero San Luis, Ich-ek, San Juan Bautista Sahcabchen of the municipality of Hopelchen in the period from January to December 2017, and with complete family clinical record; All patients who migrated from the population or abandoned prenatal care were excluded.

The variables to be investigated were the following: Urinary tract infection, Anemia, Vaginitis, Preterm birth, IUD and hormonal contraception.

The information was collected through a questionnaire that specifically included the data to be studied: Gynecological-obstetric history, Urinary tract infection, Anemia, Vaginitis, Preterm birth, IUD and hormonal contraception.

The information collected in the data collection sheets is presented through graphics made with Microsoft Office 2000 Windows XP software, its analysis was through the statistical method of measures of central tendency.

\section{Results:-}

During the period from January to December 2017 at the Ich-Ek clinic, Campeche identified a total of 32 patients with the diagnosis of adolescent pregnancy or early pregnancy.

The complications of pregnancy in adolescents in the study performed were the following:

1. Vaginitis present in 8 patients $(25 \%)$.

2. Urinary tract infection in 7 patients $(21 \%)$.

3. Anemia was present in 3 patients $(9 \%)$.

4. Like preterm birth in 1 patient $(3 \%)$, 
5. And finally 1 patient with product with low weight for gestational age (3\%)

6. Prolonged labor 1 ocation (3\%).

7. Pelvic product in 1 adolescent (3\%).

8. Contraction dystocia $1(3 \%)$.

The age with the highest incidence of pregnancy was between 17 (48\%) and $18(32 \%)$ years of age and represented the total of pregnant women.

According to the pregnancy resolution we find the following:

1. 28 vaginal births. (87\%)

2. 3 Caesareans (9\%): pelvic product, contracture dystocia, prolonged labor.

3. 1 Abortion $(3 \%)$.

Regarding the use of contraceptives, it was observed that:

1. 11 patients (34\%) used the Intrauterine Device.

2. 10 patients (31\%) used Preservative (male condom).

3. 8 patients $(25 \%)$ do not use any contraceptive method

4. 3 patients (10\%) used Bimonthly Injectable Hormone.

\section{Discussion:-}

1. In our study we observed that the main complication of pregnancy in adolescents is acute vaginitis. This is also frequent in the consultation of pregnant women over 19 years of age.

2. We also find among other urinary tract infections, anemia, premature births.

3. Pregnancy in precocious adolescents is a public health problem worldwide. In Latin America, the average age of onset of sexual activity is 17 years for women and 15 years for men. $90 \%$ of males at 19 have already had sexual experience and in women $45-65 \%$.

4. When we carried out the review of similar studies, we found congruences with the results, such as the one carried out in Mexico City at the National Institute of Perinatology, from June 2016 to May 2017, where vaginosis and vaginitis were the main ones in 328 pregnant women. to $29.3 \%$

5. In similarity with this another study is performed with the difference that the population of pregnant women is the age group ranging from 22 years to 32 years of age where here we find that urinary tract infections is the most frequent not being able to determine the reason for the variation with the other study performed.

6. With respect to the use of contraceptive methods, we obtained that the intrauterine device is the most frequent in adolescent women with little difference in percentage with those who use the condom.

7. The study carried out in the city of Morelos in 2006 by the Secretary of Public Health conducting a comparative study of unwanted pregnancy in adolescents with the use of contraceptive method repeats the result with the IUD with greater use.

8. According to the results obtained, vaginitis is the most frequent complication in pregnancy, documented in medical literature and demonstrated by study, due to the changes that occur in the vaginal canal sometimes combined with inappropriate sexual practices of women.

\section{Conclusion:-}

1. It was found that the most frequent complication was acute vaginitis.

2. Pregnancy in adolescent represented $39 \%$ of the total of annual pregnancies.

3. Vaginal delivery was the main resolution of pregnancy.

4. The age with the highest incidence of pregnancy was between 17-18 years of age.

5. The intrauterine device was the contraceptive method most used by adolescents after childbirth.

I agree with other authors on the need to investigate more about the determinants and repercussions of teenage pregnancy, and to evaluate the feasibility of introducing into the school program from the last grades of primary education, sexual education methods that prepare the adolescent for the taking of awareness of their capacity to exercise their sexuality and deliberately plan the postponement of their fertility. 
Annexed

Graph 1:-

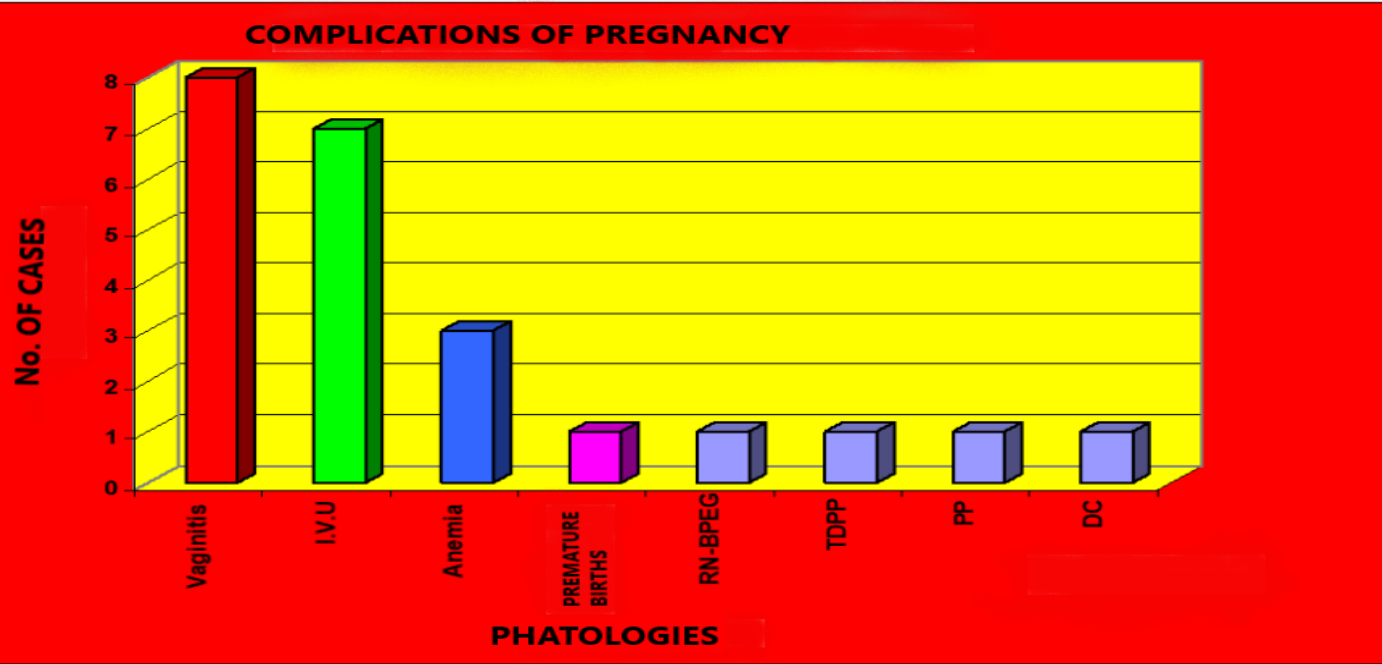

Source: Sispa 2017

\section{Graph 2:-}

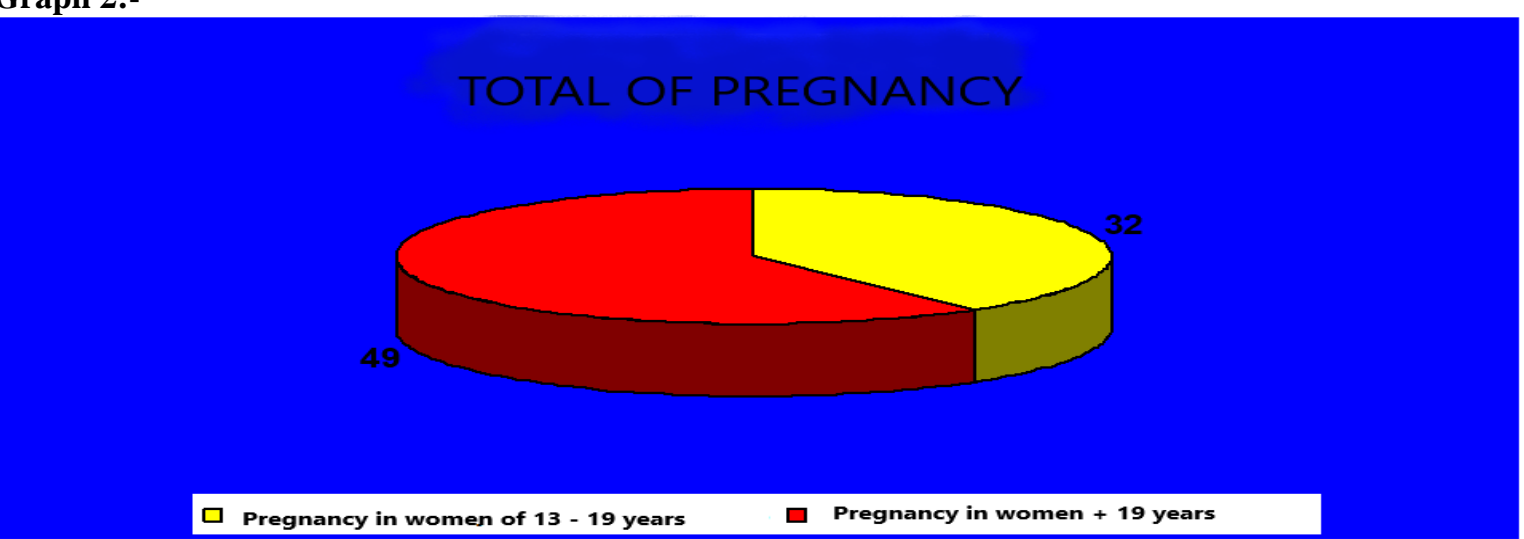

Source: SISPA 2017

\section{Graph 3:-}

\section{POSTPARTUM CONTRACEPTIUM METHODS}

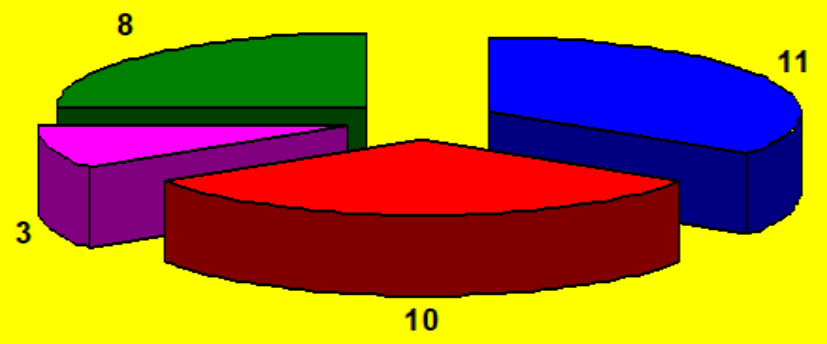

- DIU

$\square$ Preservative

$\square$ Bimonthly hormonal injection

$\square$ None 
Source: Sispa 2017

Graph 4:-

\section{INCIDENCE OF PREGNANCY BY AGE}

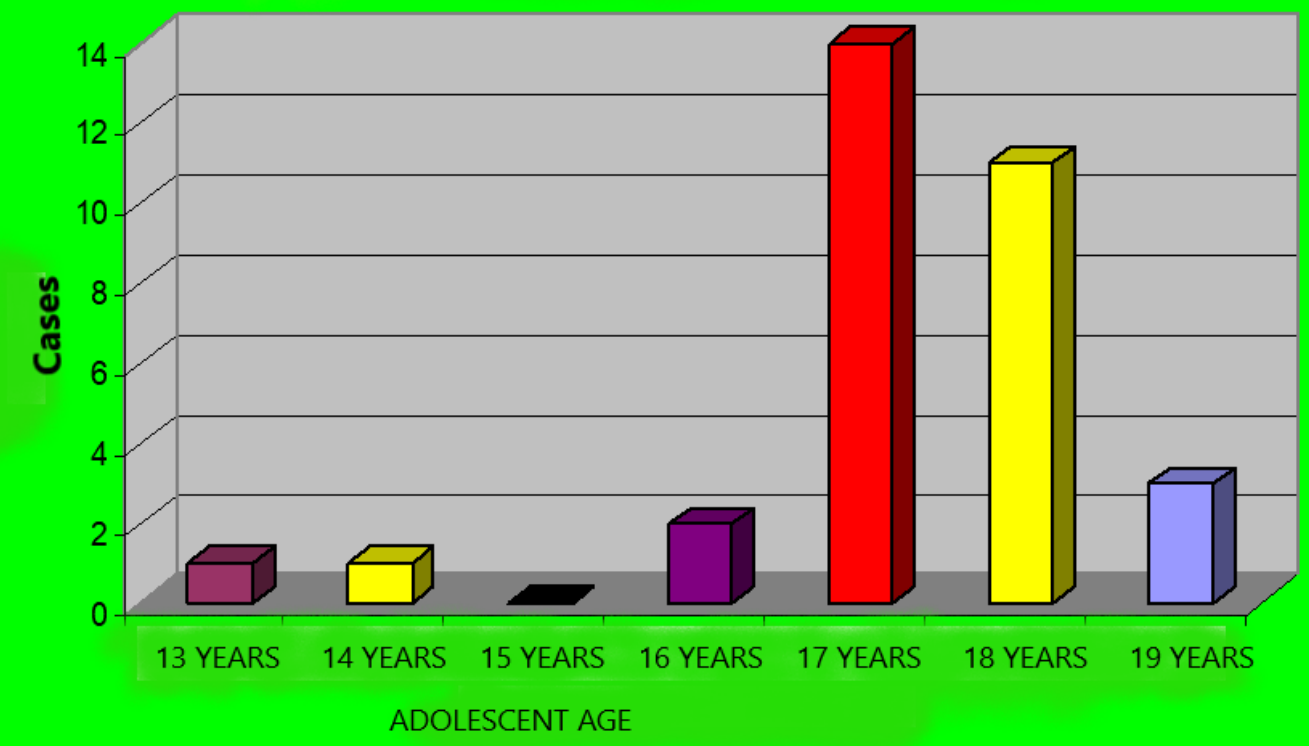

Source: Sispa 2017

\section{Graph 5:-}

\section{RESOLUTION OF PREGNANCY IN ADOLESCENT}

口|BIRTH A. 口CESAREA IABORTION

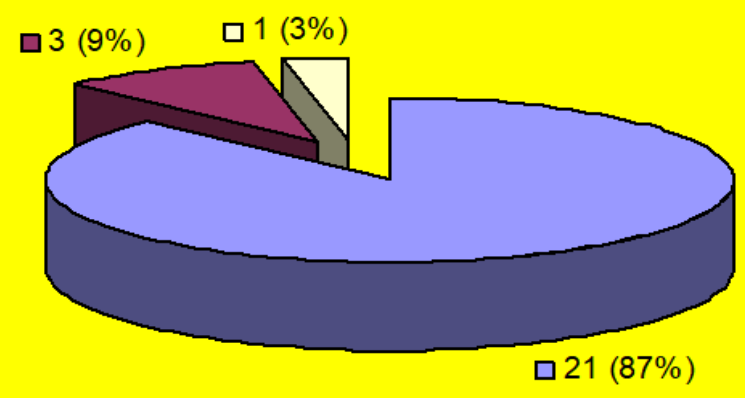

Source: Sispa 2017

\section{Bibliográphic Refeerences:-}

1. Luz Beltrán Molina, Embarazo en Adolescentes, Fundación Escuela de Gerencia Social Ministerio del poder popular para la planificación y desarrollo,Agosto 2006;1-9.

2. Ana Ledesma, Cristina Fenucci, Guia para la Atención de la adolescente embarazada y su hijo. México 2007. 34.

3. Lourdes Tisiana Monzón, Riesgos en el Embarazo Adolescente Revista de Posgrado de la VIa Cátedra de Medicina - $16 \mathrm{~N}^{\circ} 153$ - México Enero 2006. 5-6. 
4. Josefina Lira Plascencia, Dr. Héctor Oviedo Cruz,Implicaciones perinatales del embarazo en la mujer adolescente. Federacion Mexicana de Ginecologia y obstetricia 2005;73:407-14.

5. Núñez-Urquiza RM, Hernández-Prado B, Embarazo no deseado en adolescentes y utilización de métodos anticonceptivos posparto.Instituto Nacional de Salud Pública, Cuernavaca, Morelos, México 2007. 5-15.

6. Isaura Pérez. Incidencia de Embarazo Precoz según las Etapas de la Adolescencia. Departamentos de Cirugía y Pediatría, Hospital Rafael Zamora Arévalo. México 2007. 2.

7. Edgar Diaz-Franco. Guia clinica de intervencion psicologica del embarazo en la adolescencia. Perinatol Reprod Hum 2007; 21: 100-110.

8. Mark Gibson, MD. Management of Abnormal Uterine Bleeding. Clinical obstetrics and gynecology 2005; 48 11(2): 25-257.

9. Lao TT, Ho LF. The obstetric implications of teenage pregnancy. Hum Reprod 2007;12:2303-5.

10. Lira PJ, Simon PLA, Coria SI, Zambrana CM, Ibargüengoitia OF. La adolescente y el uso de dispositivo intrauterino en el puerperio inmediato. Seguimiento de un año. Ginecol Obstet Mex 2007;69(Suppl 1):7.

11. Lira PJ, Oviedo HC. Control prenatal en la adolescente. Coordinación para la atención de la paciente adolescente (serial online) 2006 noviembre. 